\title{
La Literatura Judia Helenística
}

\author{
Antonio Piñero \\ Universidad Complutense de Madrid
}

PINERO, A. La literatura judía helenística. Classica, Belo Horizonte, $3: 129-135,1990$.

RESUMO: O presente trabalho, texto de conferência proferida durante a I Semana de Estudos Clássicos da UFMG, apresenta quadro panorâmico sobre a situação, as perspectivas e o interesse do estudo da literatura judaico-helenística.

Cuando consideramos al Nuevo Testamento en sí mismo, como un corpus de escritos aislados de su entorno cultural, nos parece un producto novedoso dentro de la historia de las Religiones: el universalismo de su salvación, que abarca a todos los hombres, el amor al prójimo sin fronteras, incluido el amor a los enemigos, las concepciones morales estrictas, sus relaciones filiales con la divindad... todo ello nos hace pensar de inmediato en una enorme distancia y en una gran ventaja moral del Nuevo Testamento sobre el Antiguo.

Pero, ¿es correcta esta comparación? ¿No habría también que comparar el ideario cristiano con la literatura religiosa de la época helenística/romana y con la literatura judía helenística? En principio podemos pensar que productos religiosos de una misma época $y$ de una misma cercanía geográfica tengan que ver entre sí. Sin embargo, hasta época muy reciente - prácticamente en este siglo, y de un modo intenso desde 1970 - no se ha contrastado suficientemente el corpus neotestamentario con esta literatura judía helenística. $Y$ este precisamente va a ser el intento de la presente conferencia, aunque de un modo somerísimo, dadas las naturales limitaciones de tiempo. Aludiremos también de pasada a algunas 
deudas religiosas que el judaismo en general contrajo con el entorno de las religiones y pensamiento helenísticos y que en buena parte pasaron al acervo ideológico del cristianismo.

Pero, en primer lugar, debemos indicar brevemente qué es esta literatura helenística. Llamamos así, o también "Apócrifos o Pseudoepigráficos del Antiguo Testamento", la producción literariareligiosa que generaron diversos grupos judíos en el marco temporal de los siglos III a. C. hasta el s. II d. C. Esta literatura pretendió ser la expressión religiosa de ciertos espíritus que intentaba continuar, complementar y ampliar la línea teológica del Antiguo Testamento. La mayoria de estas obras fue redactada en hebreo/arameo y unas pocas en griego helenístico. El original semítico, sin embargo, de muchas ellas se ha perdido y el pensamiento original se nos ha conservado y transmitido bajo la mediación de versiones muy antiguas y venerables al etíope clássico, al griego, al latín, copto, siríaco y eslavo antiguo. Ha sido precisamente la Iglesia cristiana, y no la Sinagoga oficial, la que nos ha transmitido estos escritos. El judaismo fariseo oficial, que predominó y conformó el judaismo tras la toma de Jerusalém por Tito en el 70 a. C., no quiso saber nada, o casi nada, de este tipo de escritos que consideró poco interesantes o heterodoxos. La Iglesia cristiana, sin embargo, los conservó, ya fuera porque consideró a algunos de ellos como inspirados, o porque les parecieron una nutritiva lectura espiritual.

$\mathrm{Y}$ ¿cuáles son estos escritos y cómo pueden catalogarse? En general puede decirse que se corresponden con géneros conocidos desde el AT. Así tenemos: A) Ampliaciones del AT y otras leyendas: Libro de los Jubileos, Martirio y Ascensión de Isaías, Novelas de José y Asenet, Vida de Adán y Eva, Antigüedades Judias del Ps. Filón. - B) Literatura profética y apocalíptica: Ciclo de Henoc, Oráculos sibilinos judios, Libro $4^{\circ}$ de Esdras, Libros 2: y 3 de Baruc, Apocalipsis de Adán, Abrahán, Elías y Daniel. C) Literatura de "Testamentos": Testamento de los XII Patriarcas, Test. de Job, Test. de Salomón, de Moisés, de Adán. - D) Literatura Sapiencial y filosófica: Libros $3^{\circ}$ e $4^{\circ}$ Macabeos, Ps. Focílides. E) Oraciones, Salmos y Odas: Nuevos Salmos de David, Oraciór de Manasés, Salmos de Salomón. Odas de Salomón. 
¿Cómo son accesibles hoy estas obras? Existen diversas series en lenguas modernas que ofrecen una traducción fiable, a veces con introducciones y notas, de estos textos antiguos. Las principales son las siguientes: P. Riessler, Altjüdisches Schriftum ausserhalb der Bibel (Heidelberg 1966), W. G. Kummel, Judische Schriften aus hellenistischer Zeit (Gütersloh 1975-1988), J. H. Charlesworth, The Old Testament Pseudepigrapha (N. York 1983-4), A. Díez Macho y Colaboradores, Apócrifos del Antiguo Testamento (Madrid, Edic. Cristiandad 1982-7) .

Como puede observar el lector este tipo de obras se ampara en el nombre de venerables personajes del Antiguo Testamento, por lo que son claramente pseudoepigráficas. ¿Quiere decir esto que sus desconocidos (para nosotros) autores trataban positivamente de engañar a sus lectores y a la posteridad con una falsa atribución de sus obras? Nada de eso. El concepto de "falso" era muy distinto en la Antigüedad al de hoy día. En general los autores de estas obras las ampararon bajo el escudo de personajes gloriosos del pasado porque estaban convencidos que ellos habían hecho llegar hasta el autor del momento parte de su espíritu profético y religioso. Cualquier escrito que se compusiera con la inspiración de ese espíritu, transmitido a través de los siglos, podía atribuirse sinceramente a un personaje religioso pasado sin ánimo de dolo. Por otro lado, como hacia el s. III a. C. existía ya la idea clara de que la revelación oficial había concluido ya en Israel y que para el futuro profetas y hagiógrafos no habrían de existir (puesto que ya nada podía revelarse que no estuviera en la Torá) era lógico que nuevas producciones sobre temas religiosos hubieran de ampararse bajo el nombre de personajes que aún existían cuando se hallaba abierta la revelación. Bajo este aspecto, pues, debemos considerar el fenómeno de la pseudoepigrafía y no interpretarlo como un intento positivo de engaño.

Esta literatura helenística había recibido de la atmósfera religiosa y cultural del helenismo una fuerte impronta. Así del platonismo popularizado el judaismo había aceptado la idea de una más clara división del compuesto humano en alma y cuerpo y una creencia firme en la inmortalidad del alma, lo que aparejaba consigo la defensa de la resurreción, al menos de la parte más 
noble del hombre: su espíritu. La creencia antigua judía en los ángeles (heredada de Babilonia) se vió potenciada por la difusión de las idéas en torno a los démones en la doctrina platónica tardía. Estos seres se dividían en buenos y malos, y tenían como tarea principal ayudar o impedir a los hombres un acercamiento a la divindad. La cosmología platónica, con su radical división entre este mundo degradado y perecedero y el mundo superior y divino de las ideas, contribuyó también enormemente a afianzar las directrices ascéticas de huida del mundo presente que debían hacerse vivas en el judaismo helenístico y luego en el cristianismo.

De la difusión de la filosofía estoica el judaismo se aprovechó principalmente en el terreno de la ética. Es bien sabido que la moral ocupaba un puesto de honor en los sistemas cínicos y estoicos y que eran de hecho las normas y aforismos morales lo que difundían sobre todo los predicadores ambulantes estoicos. Así, las virtudes cardinales, y la imperturbabilidad, junto con el ideal del sabio (como hombre totalmente centrado en la virtud y lo espiritual) habrían de pasar a formar una constelación moral de virtudes de la que participó ampliamente el judaismo helenístico.

Por otro lado, la difusión de ideas pitagóricas y sobre todo la expansión de las teogonías órficas en el Helenismo contribuyeron notablemente a difundir las ideas ya tradicionales sobre la vida de ultratumba. La inmortalidad del alma era idea clara entre neopitagóricos y órficos y la creencia en el "averno" circulaba como moneda corriente. Los órficos afirmaban, con la tradición, que el infierno se encontraba en lo más profundo de la tierra, y que era un lugar donde los malvados sufrían los peores tormentos. En el libro $1^{\circ} d e$ Henoc, en la tradición evangélica y en el Apocalipsis de Pedro (que casi llegó a entrar en el canon neotestamentario) encontramos reflejos tardíos pero vigorosos de estas concepciones tradicionales en diversas culturas religiosas del ámbito mediterráneo.

Además, la literatura judía helenística presenta una serie de rasgos teológicos peculiares que, simplemente enumerados, ayudarán al lector a comprender en qué ambiente espiritual se plasmaron una serie de teologuemas que se hallan en el NT. Estas ideas son las siguientes: 1) Espera febril en un fin del mundo cercano. Habrá pronto un cambio total y repentino de las condiciones de la vida 
humana. - 2) División del tiempo del mundo en dos períodos antogónicos, cuyo contenido está predeterminado desde la creación: el tiempo presente, malo y perverso, y el futuro, de bienandanza para los buenos o elegidos. - 3) El fin del mundo se deberá a una conflagración. El mundo va siempre a peor. Pero la catástrofe final significará liberarse del Malvado. - 4) Mientras dure este tiempo y este mundo existe una dualidad de fuerzas que combaten entre sí: Dios/Mal; espíritu/carne; luz y tinieblas; vida y muerte, etc. - 5) Existencia de seres intermedios entre Dios y los hombres: hay ángeles y demonios. Estos influyen en la marcha de este mundo. La derrota final de los malos espíritus es segura, $\mathrm{y}$ en el mundo futuro sólo tendrán participación los buenos. 6) Tras la catástrofe final habrá una salvación paradisíaca. El resto de Israel que sobreviva se salvará. La catástrofe significará el término del tránsito entre la creación y la salvación. Acabará el tiempo y quedará abolida la distinción entre historia celeste y historia humana. - 7) Existe, además, un intermediario con funciones reales o sacerdotales (o ambas). Este será el garante y ejecutor de la salvación final. Esa figura se llamará Hijo del Hombre, Mesías o el Profeta... y su naturaleza no queda clara: humana o angélica. - 8) El estado final de los humanos elegidos será el de una gloria sin fin e inmarcesibles.

Como puede observar el lector, sin precisar más bagaje que algunas lecturas someras del NT y la reflexión sobre la tradición cristiana, esta ideología ha pasado en gran parte al mundo neotestamentario. Pensemos además que un escrito canónico del Nuevo Testamento, la Epístola de Judas, cita como canónico al libro de Henoc, y probablemente también a la Ascensión de Moisés. No es extraño, por tanto, que se recibieron estas ideas con gusto en ámbito cristiano. Y no solamente las ideas de tono general, sino algunos pasajes neotestamentarios se aclaran perfectamente haciendo referencia a textos anteriores cronológicamente al cristianismo. Vamos a reducirmos a poner tan sólo unos cuantos ejemplos. La pregunta formulada en 1 Cor 15,35-40, con qué cuerpo habrán de resucitar los muertos, se explica por una misma preocupación que se reflejaba en ambientes judíos, tal como testimonia posteriormente 2 Baruc 49,2-3. ¿Hasta cuando ha de esperar la sangre de los mártires? 
se pregunta el autor del Apocalipsis de Juan (6,9-11), cuestión que tiene su paralelo y comentario en 4 Esdras 4,34-36. En el Testamento de Abrahán, el héroe ve cómo muchos caminan por la puerta ancha de la perdición y pocos por la estrecha (Lc 13,23). La expresión de Mc 9,1: "Algunos de los aquí presentes no gustarán de la muerte antes de que venga el reino de Dios con poder", tiene su correspondencia en 4 Esdras 8,61-63 y en 2 Baruch 85,10. Toda la imaginería de Mc 13 (batallas finales, guerras fratricidas entre pueblos) es parecida a la que hallamos en Orac. Sibil. 3,635 y 1 Henoc 99,4. La teología de los Evangelios Sinópticos sobre el Hijo del Hombre no se explica sino como una reflexión y acomodación de la doctrina al respecto que se halla en el Libro canónico de Daniel (escrito hacia el 168 a. C. y que pertenece a esta literatura apocalíptica judía) y en el llamado "Libro de las Parábolas" del 1 de Henoc. Las desventuras de las riquezas, que tan presentes están en el Evangelio de Lucas tienen un claro antecedente en la sección 92-105 del 1 Henoc. Igualmente una descriptión de la Nueva Jerusalén parecida a la del Apocalipsis de Juan (cap. 20 ss) se halla en la Ascención de Moisés, 10. La Eucaristía cristiana como pan de vida y vehículo de la inmortalidad tiene textos de sorprendentes similitudes en la Novela de José y Asenet, caps. 9 y 15. El género judío helenístico de los "Testamentos" se reproduce en Jn 13-17, en Hechos 20,17 ss (Pablo en Efeso), en Lc 22,15-38, etc., por no hablar de $1^{\text {a }}$ y $2^{\text {a }}$ a Timoteo y el "testamento" de Pedro en 2 Pe 1,13-15. La ética cristiana en lo que respecta a la vida sexual, más rigurosa que la del entorno común judío, tiene claros antecedentes en el Testamento de Rubén y en el Testamento de José.

Hasta aquí hemos tratado solamente de un tipo de literatura que, como indicábamos más arriba, suele conocerse como "apócrifos del Antiguo Testamento". Pero desde 1948, una de esas maravillosas casualidades que de vez en cuando nos depara la vida proporcionó a la ciencia uno de los descubrimientos de manuscritos más importantes de los últimos tiempos: los textos de Qumrán o Manuscritos del Mar Muerto. Estas obras fueron prácticamente todas escritas en hebreo o arameo y entre ellas se encuentran representados muchos fragmentos de los que hemos denominado "apócrifos". Su período de composición va desde el s. II a. C., comienzos de la secta de los 
esenios - autores de estos escritos —, hasta el 68 d. C., año final de la secta, dispersada o aniquilada por las tropas romanas de Vespasiano y Tito. Entre los escritos más importantes, que merecen una comparación detenida con la teología cristiana, destacan: el Manual de Disciplina o Regla de la Comunidad, El Rollo de la Guerra, los Himnos y los Comentarios a los Profetas.

Los contactos entre el cristianismo y la teología de Qumrán son tantos que se ha supuesto que Jesús no era más que un miembro independiente de esa secta. Las concepciones apocalípticas y escatológicas son comunes, así como la doctrina de los "novísimos". Igualmente muchas ideas en torno a Dios, angelología, ética, espectativas mesiánicas, organización de la comunidad y esperanza en la venida inmediata del reino de Dios son muy similares. No podemos deternermos aquí en una comparación detallada de ambos corpora, el qumránico y el neotestamentario, porque ello excedería con mucho los límites de esta conferencia. Pero baste saber que este tipo de literatura helenística judía, aunque escrita en lengua semítica, tiene estrechísimos contactos con la teología del NT. El interesado puede ahondar en el tema consultando el claro y provechoso libro de A. González Lamadrid, Los Manuscritos del Mar Muerto. Balance de 25 años de hallazgos y estudios. Madrid (BAC) 1973.

Debemos volver ahora a lo que es el título de esta conferencia y afirmar, gracias a la comparación aquí hecha de ideologías, que la madre más próxima y verdadera de la teología neotestamentaria no se halla directamente en el Antiguo Testamento, sino en todo este bloque de literatura judía helenística que continúa, prolonga, corrige y amplía la teologia del AT. Pero debido a las diferencias entre el cristianismo y esta literatura (a las que no hemos podido aludir por falta de tiempo) no podemos afirmar que el cristianismo sea una mera continuación de esta literatura, ni mucho menos una copia directa, por ejemplo del ideal esenio, como algunos han pretendido. Más bien nos debemos imaginar el proceso del modo siguiente: en época helenística tardía y durante los primeros años del Imperio Romano el judaismo no formaba un bloque homogéneo. Era más una ortopraxia que una ortodoxia. El judaismo de entonces estaba dividido en múltiples sectas y variadas corrientes ideológicas. Era como un árbol frondosísimo 
con abundantes ramos de diverso grosor. De ningún modo era una especia de monolito (idea que nos formamos espontáneamente considerando el judaismo actual, heredero de una de aquellas ramas, la farisaico-hillelita, y que retrotraemos equivocadamente hacia comienzos de nuestra era) sino un conjunto heterogéneo. Pues bien, el cristianismo era una rama más, aunque algo especial, de ese árbol frondoso. Debieron pasar algunos años hasta que los cristianos fueran excluidos oficialmente, como herejes, de la Sinagoga. $\mathrm{Y}$ precisamente porque el árbol tenía muchas ramas, las doctrinas de cada una de ellas contienen muchos puntos semejantes, sin que pueda hablarse de copia. Todas ellas eran el reflejo de un ambiente común. Ahora, como muchas de estas obras judías helenísticas son anteriores al cristianismo, puede decirse que los teologuemas que en ellas encontramos y que luego son aceptados por el cristianismo son, hasta un cierto punto, el magma o la madre en los que se moldea la teología cristiana. Esto nos lleva también a la conclusión de la necesidad de estudiar este tipo de literatura judía si queremos enterarnos bien de las raices cristianas y del alcance de suas aportaciones. Incluso en unos ambientes donde predomina la filología clásica sobre la filología semítica no están de más estos tipos de estudios, ya que, al fin y al cabo, el Nuevo Testamento fue íntegramente redactado en griego, y gran parte de esta literatura judía helenística se ha transmitido en esta lengua y en latín.

Conferência proferida durante a I Semana de Estudos Clássicos da UFMG, em 07/10/1988, em Belo Horizonte.

Aceito para publicacão em $20 / 06 / 89$ 